\title{
Coccygeal Sinus
}

National Cancer Institute

\section{Source}

National Cancer Institute. Coccygeal Sinus. NCI Thesaurus. Code C118309.

A blind-ending, epithelial-lined tract that is located less than $5 \mathrm{~mm}$ from the anal verge. 